\title{
Neuropatía óptica severa por etambutol
}

\section{Severe optic neuropathy by ethambutol}

\section{Rachid Bouchentouf' y Mohamed Kriet ${ }^{2}$}

Bouchentouf R, Kriet M. Neuropatía óptica severa por etambutol. Rev Soc Peru Med Interna. 2020;33(1):51. https://doi.org/10.36393/spmi.v33i1.513

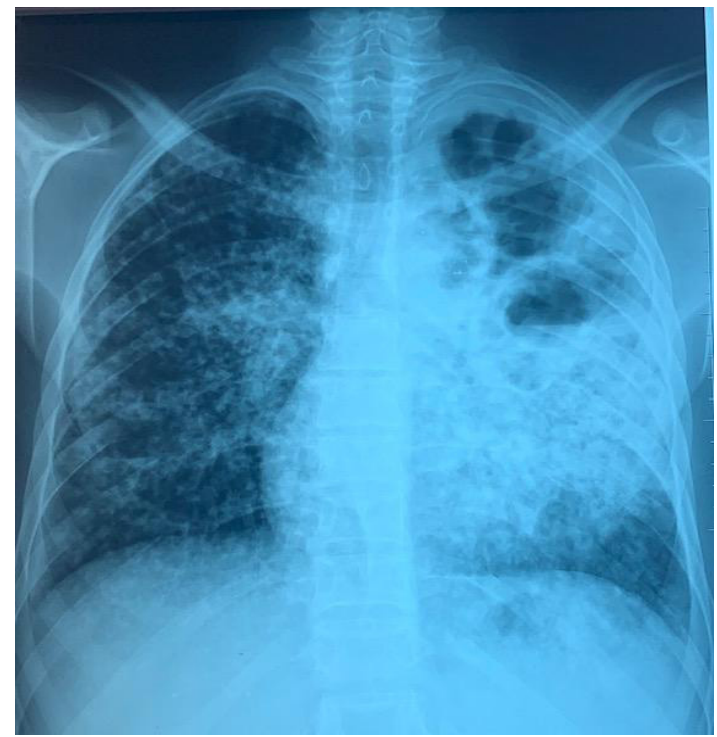

Figura 1. Rx. de tórax. Tuberculosis pulmonar activa.

Un varón de 51 años de edad con antecedentes de tuberculosis (TB) pulmonar en el año 2000, tratado por régimen $2 \mathrm{RHZE} / 4 \mathrm{RH}$. Presentó una recurrencia de TB con baciloscopía positiva y sensible a la rifampicina (Figura 1). Recibió etambutol (15 mg/ $\mathrm{kg} / \mathrm{día})$, isoniacida (300 mg/día), rifampicina $(600 \mathrm{mg} /$ día $)$ y pirazinamida $(25 \mathrm{mg} / \mathrm{Kg} /$ día $)$, más piridoxina $150 \mathrm{mg}$ / día. Tres meses después, el paciente presentó pérdida de la agudeza visual (AV) en ambos ojos (AO): 1/10 ojo derecho y 2/10 ojo izquierdo. Presión intraocular normal y la biomicroscopía mostró un defecto pupilar aferente en ojo derecho. Campimetría: un escotoma central y bilateral en AO. Fondo de ojo: papilas pálidas de contornos regulares y maculas normales (Figura 2).

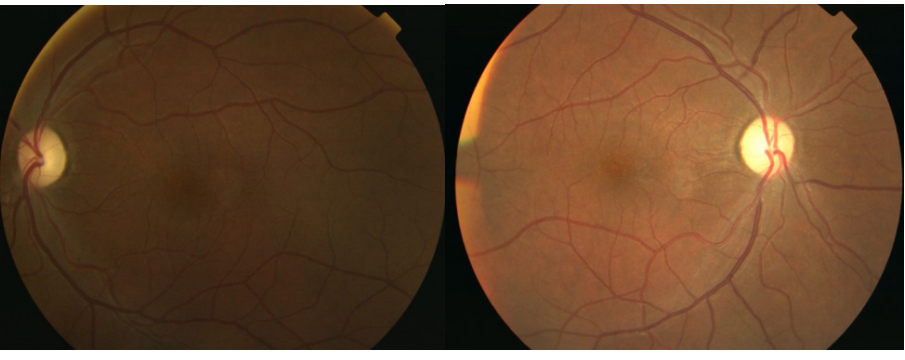

A. 0jo izquierdo B. 0jo derecho

Figura 2. Papilas pálidas y de contornos regulares, máculas normales en ambos ojos

Test de Farnsworth: discromatopsia. Potenciales evocados visuales: alteración axonal afectando a los fascículos maculares. RMN cerebral y de las órbitas: normales.

Se diagnóstico una neuropatía óptica causada por etambutol. Este se interrumpió y se continuó con rifampicina e isoniacida durante seis meses. Después, hubo una mejora de la AV (4/10 ojo derecho y 5/10 ojo izquierdo).

La neuropatía óptica tóxica por etambutol puede afectar al $1 \%$ de los pacientes cuando la dosis supera los $15 \mathrm{mg} /$ $\mathrm{kg}$ /día y en tratamiento prolongado. Ambos ojos suelen ser afectados simétricamente y las pupilas pueden estar ligeras o moderadamente arreactivas. Los escotomas centrales son los defectos más frecuentes del campo visual. La forma más eficaz de tratamiento de esta neuropatía es la interrupción del etambutol.

\section{REFERENCIAS BIBLIOGRÁFICAS}

Rodríguez-Marco N.A, Solanas-Álava S, Ascaso F J, Martínez-Martínez L, Rubio-Obanos M.T, Andonegui-Navarro J. Neuropatía óptica severa y reversible por etambutol e isoniazida. An Sist Sani Navar. 2014; 37 (2): 287-291.

Hernández Prats, Escrivá Moscardó S, Martínez Pastor, Pampliega Pérez A. Toxicidad óptica por etambutol. Farm Hosp. 2006; 30: I-2. 